\title{
Формирование волновых пакетов с большой энергией импульсов при генерации случайных импульсов в волоконных лазерах
}

\author{
$\underline{\text { И.А. Волков }}^{1, *}$, В.А. Камынин ${ }^{2}$, С.Н. Ушаков ${ }^{1,2}$, К.Н. Нищев ${ }^{1}$, В.Б.Цветков ${ }^{2}$ \\ ${ }^{1}$ Нацииональный исследовательский Мордовский государственный университет, \\ Саранск, Россия \\ ${ }^{2}$ Институт общей физики им. А.М.Прохорова РАН, Москва, Россия \\ *E-mail: emofan_80@mail.ru
}

DOI: 10.31868/RFL2020.81-82

Волоконные лазеры с пассивной синхронизацией мод являются хорошими платформами как для генерации новых импульсных режимов, так и исследования взаимодействия ультракоротких импульсов. В последние годы возрос интерес к изучению режима работы волоконных лазеров с пассивной синхронизацией мод, при котором генерируются шумоподобные импульсы. Этот режим работы волоконных лазеров привлекает внимание из-за его особенностей: генерация широких спектров [1], высока энергия импульсов [2] низкая временная когерентность [3]. Другим важным режимом в волоконных лазерах с пассивной синхронизацией мод является гармоническая синхронизация мод, представляющая собой серию периодических импульсов с частотой повторения, которая является целым кратным основной частоты резонатора [4]. Несмотря на то, что гармоническая синхронизация мод не является эксклюзивом для солитонных лазеров, является особенно привлекательной для оптической связи [2].

В данной работе представлены результаты исследования лазерной генерации волоконного $\mathrm{Er} / \mathrm{Yb}$ лазера c пассивной синхронизацией мод. Экспериментальная установка показана на рис. 1.

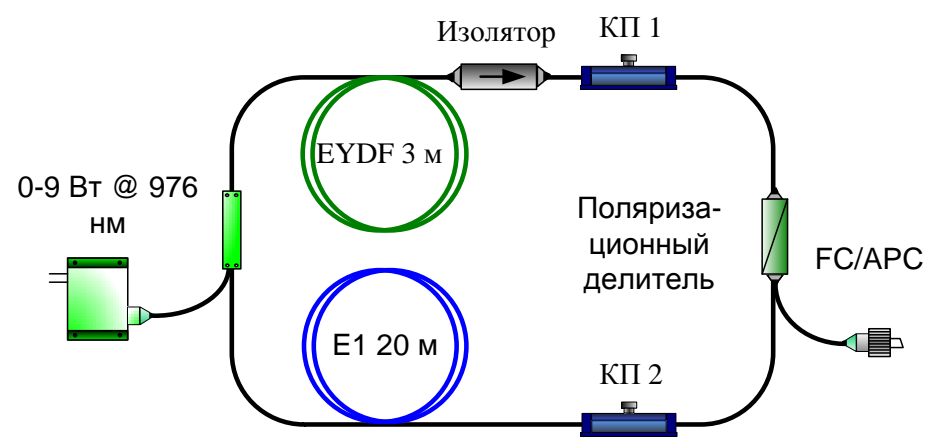

Рис. 1. Схема экспериментальной установки.

Синхронизация мод достигается за счет совместного действия нелинейного вращения плоскости поляризации и дискриминации поляризационных состояний внутрирезонаторными контроллерами поляризации. Резонатор лазера представляет собой однонаправленное кольцо, которое включает в себя: $\mathrm{Er} / \mathrm{Yb}$ волокно, одномодовое волокно $\mathrm{E} 1$, изолятор, делитель поляризации и два контроллера поляризации. Общая длина резонатора составила $\approx 27$ м. Для накачки использовался лазерный многомодовый диод, работающий на длине волны 976 нм с выходной мощностью до 9 Вт. Излучение накачки вводилось в резонатор при помощи объединителя накачки с сигнальной жилой $(2+1) \times 1$.

При тщательной подстройке контроллеров поляризации и контроле мощности накачки достигались как стационарные, так и нестационарные режимы 
генерации. На рис. 2 представлен оптический спектр, простирающийся на 200 нм, измерение которого ограничено с правой стороны диапазоном спектр анализатора. Пара пиков вблизи 1536 нм и 1543 нм соответствует остаточному непрерывному излучению. Спектральная ширина на уровне 3 дБ спектра составляет 52 нм, а на уровне 20 дБ - более 200 нм. Оптический спектр ассиметричен и в длинноволновой области присутствует пик в области 1,65 мкм, связанные с внутриимпульсным комбинационным рассеянием.
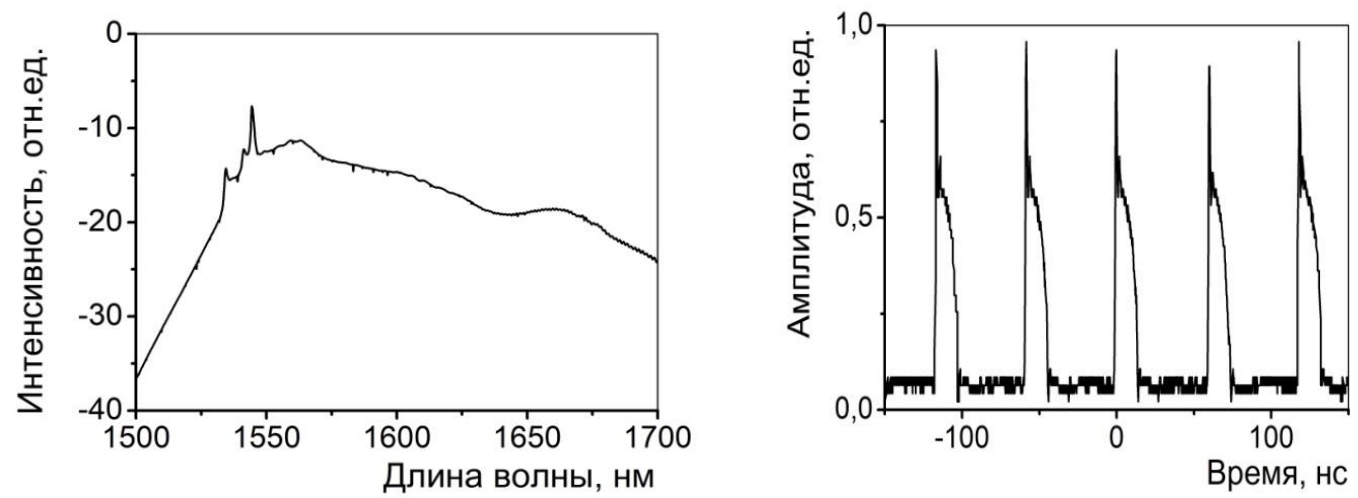

Рис. 2. Оптический спектр и осциллограмма импульсов.

На рис. 2 (б) представлена осциллограмма стабильной импульсной последовательности с периодом $\mathrm{T} \approx 60$ нс (16,6 МГц), что не соответствует периоду обхода резонатора $\mathrm{T} \approx 120$ нс (8,3 МГц). Данный импульсный режим соответствует гармонической синхронизации мод. Ширина временного профиля импульса на уровне FWHM $\approx 13$ нс. Максимальная выходная мощность составила $\approx 300$ мВт при мощности накачки 6,5 Вт. Энергия одиночного импульса в режиме оценивается в 20 нДж.Учитывая характеристики оптического спектра и временного профиля, можем предположить, что данный импульс является шумоподобным. Как было показано в работе [5], динамика шумоподобных импульсов обладает внутренними механизмами - нелинейностью, локализацией и хаосом, которые способствуют формированию волн-убийц, при этом основной механизм состоял в том, что происходило перераспределение плотности энергии посредством столкновений внутри «банча» импульсов, в то время как полная энергия «банча» импульсов остается приблизительно постоянной. На основании [5] мы ожидаем, что при генерации шумоподобного импульса в аномальной дисперсии происходит сжатие солитонных импульсов для генерации оптического спектра с большой спектральной шириной, сопровождающееся внутриимпульсным комбинационном сдвигом и, как следствие, к разрыву импульса внутри «банча», распространяющегося по волоконному резонатору.

\section{Литература}

[1] H. Santiago-Hernández, O. Pottiez et al, Laser Phys., 25(4), 045106, (2015)

[2] J. P. Lauterio-Cruz, O. Pottiez et al, Optics Express, 24 (13), 13778-13787, (2016)

[3] Y. J. You, C. Wang et al, Lasers and Electro-Optics (CLEO), Technical Digest (Optical Society of America, 2015), paper JW2A.94

[4] A. Komarov, A. Haboucha, and F. Sanchez, Opt. Lett. 33(19), 2254-2256 (2008)

[5] C. Lecaplain, Ph. Grelu, Physical Review A 90, 013805, (2014) 